\title{
SERVQUAL- Model- Based Fuzzy Evaluation of Express Service Quality
}

\section{Ji Xuehua}

Business School, Beijing Wuzi University, Beijing, China

\section{Email address:}

2051758359@qq.com

\section{To cite this article:}

Ji Xuehua. SERVQUAL- Model- Based Fuzzy Evaluation of Express Service Quality. International Journal of Transportation Engineering and Technology. Vol. 4, No. 1, 2018, pp. 20-23. doi: 10.11648/j.ijtet.20180401.13

Received: April 24, 2018; Accepted: May 10, 2018; Published: May 30, 2018

\begin{abstract}
According to the significance of express service, which has an impact on the high quality development of China's express delivery industry, this paper based on the quality of express delivery service problems to analyze the affecting factors and try to find out the best solution. Firstly, Based on expatiating The Service Quality (SERVQUAL) and LSQ evaluation system, an index system with five dimensions and 14 indicators indexes is designed. Then fuzzy analytic hierarchy process (FAHP) is used to determine the weight of each index and establish an evaluation model that the service quality can be fuzzily evaluated. The results show that consumers are not satisfied with the quality of current express service. With this finding, some relevant countermeasures and suggestions are proposed to improve service quality and enhance the competitiveness of express companies.
\end{abstract}

Keywords: Quality of Express Service, SERVQUAL Model, FAHP

\section{Introduction}

With the increasing popularity of the Internet, the convenient e-commerce model is gradually infiltrating people's lives and promoting the accelerated development of the express delivery industry. According to the data from the State Post Bureau, the total number of China's express delivery services reached 31.3 billion in 2016, an increase of $51.3 \%$ over the same period; the revenue from express delivery services was 397.4 billion dollars and have an increase of $43.5 \%$; The number of express delivery services completed was 40.1 billion in 2017 , an increase of $28.2 \%$ on the same time, the express delivery service revenue was 495.71 billion dollars, an increase of $24.7 \%$; In 2018, the total number of express delivery services will reach 49 billion, an increase of $22.2 \%$ year-on-year, the income from express delivery services will be 595 billion dollars and performance increase of $20.2 \%$. It can be seen that the high quality development of express delivery industry is of great significance to the promotion of high-quality economic growth in China.

Just-in-time service is used to enhance express delivery industries' performance, service level and reduce/eliminate waste from the end-to-end system [1]. Unfortunately, with the rapid development of express delivery industries, it has exposed some problems. Liu Longqing [2] pointed out that it has some problems in the existing reverse logistics, such as unstable demand, asymmetric information and unbalanced subjects. Chen Ping [3] used the analytic hierarchy process to construct campus express service quality evaluation index model, then analyzed the five indicators of "Courier fees, Delivery schedule, Parcel security, Service attitude and Propaganda". Wu Qiong [4] made a factor analysis method of logistics service quality and obtained Responsiveness, Reliability, Empathy, Assurance and Tangible weights. Finding out the key points will play an essential role in promoting the high quality of express delivery.

Therefore, the article uses SERVQUAL Model and LSQ evaluation system to analyze the quality of express delivery services, as well as conduct factor analysis. Then Fuzzy comprehensive evaluation on the questionnaire survey data to identify key points that affect the quality of express delivery services. Finally, Suggestions have been adopted to enhance Service quality and improve customer satisfaction. 


\section{Evaluation System}

\subsection{Research Status}

In order to improve the quality of express delivery service, many scholars study express delivery services from different perspectives. From the standpoint of customer satisfaction, Xie Fang [5] proceeded the five dimensions of express company, it analyzed customer's intention of repurchasing based on the original SERVQUAL model. Zheng Jianing [6] used the Likert five-point scale to quantify the subjective perception of customer service quality, Cheng gong University City Express in Kunming was used as an example to build a customer perceived index system. Fan Lixian [7] analyzed the quality of express delivery services from convenience, economy, timeliness and reliability, it has been deepened the study of customer experience by constructing a structural equation model. In order to improve the service quality of express delivery companies, Cao Xia [8] built a SERVQUAL model to construct an express service quality evaluation system under the background of online shopping. Zhao Yuzhou [9] sorts out the development status of China's express delivery. as well as combines the SF Express standard pricing mechanism with the customer's courier service demand, price survey results. In the "Internet Plus" age, the law should protect personal information, business information and operator information to promote the healthy development of the express delivery industry [10].

In summary, Domestic scholars are aware of the importance of specific service quality, at the same time, it mainly through the analysis of the qualitative to improve the quality of express delivery services. But the analysis on the combination of affecting Express service quality orientation and quantification is not enough. Therefore, the paper uses SERVQUAL model to design a questionnaire and adopts fuzzy analytic hierarchy process to analyze the data, though promoting relevant countermeasures to the high-quality development of express delivery service quality.

\subsection{Evaluation Index System}

In 1980s, Market scientist Para Solman proposed the SERVQ UAL model-Tangible, Reliability, Responsiveness, Assurance and Empathy. Tangible refers to the appearance of the facilities and staff to impress customers; Reliability means the ability of enterprises to perform high quality service; Reaponsiveness implication is that the ability of providing timely and accurating services to customers; Assurance relates to employees of Knowledge and ability that can make customers convinced; Empathy is to establish a customer philosophy, as well as provide them with personalized and diversified services. It's core is the service quality gap model, it also means that the quality of service depends on the degree of difference between the user perceived and the expected service level. This paper uses the five dimensions of the SERVQUAL model as the first-level indicators, and applies LSQ (Logistical service quality) model to establish 14 secondary symbols based on the first-level indicators, the LSQ model was proposed by MENTTZER scholar in the United States in 2001. The diagram of Express service quality system is shown in Table 1.

Table 1. Express service quality system.

\begin{tabular}{ll}
\hline First-level indicators & Second-level indicators \\
\hline & Express Service Timeliness and Convenience U11 \\
Responsiveness U1 & Courier service attitude U12 \\
& The processing of Business disputes U13 \\
& Customer Information Confidentiality U21 \\
& The delivery person image U22 \\
Reliability U2 & Product Integrity U23 \\
& Express ReasonalblePriceU31 \\
& Communication with customers U32 \\
Empathy U3 & Personalized service U33 \\
& Smoothness of Business Process U41 \\
& Customer's Property Information U42 \\
Assurance U4 & Advancement of Express facilities and equipment U43 \\
& Courier ability U51 \\
Tangible U5 & Express information feedback capability U52 \\
\hline
\end{tabular}

\section{Evaluation Model Establishment}

\subsection{Questionnaire Design}

The paper combines the SERVQUAL and LSQ models and uses the Likert scale to set up the questionnaires. College students are the subjects of the survey. Inquires are mainly based on "online e-questionnaires". The survey focuses on "Tangibility, Reliability, Responsiveness, Assurance and empathy" five areas. A total of 150 questionnaires are retrieved, 135 valid polls are obtained, this recovery rate reached $90 \%$. By analyzing, female students account for $59.3 \%$ and male students account for $40.7 \%$. It can be knew that female students are more frequent online shopping than male students, which is the main driving force for the rapid development of the express delivery industry.

\subsection{Application of Fuzzy Analytic Hierarchy Process}

The main body of this text uses the fuzzy analytic hierarchy process to solve the multi-factor and multi-level complex 
problems, so it can explain the ambiguity of multi-indicators related to express service quality. By quantitatively analyzing the quality of express delivery services, avoiding human subjective judgments to affect the verification results, it can make the results more credible.

\subsubsection{Construct Fuzzy Evaluation Factor Set and Evaluation Set}

The paper constructs14 evaluation indexes, including a first-level index $\mathrm{U}=\left\{\mathrm{u}_{1}, \mathrm{u}_{2}, \mathrm{u}_{3}, \mathrm{u}_{4}, \mathrm{u}_{5}\right\}=$

\{Very satisfied, Satisfaction, General, Dissatisfied, Very dissatified\} as well as a second-level index: $u_{1}=\left\{u_{11}, u_{12}, u_{13}\right\}$; $u_{2}=\left\{u_{21}, u_{22}, u_{23}\right\} \quad ; \quad u_{3}=\left\{u_{31}, u_{32}, u_{33}\right\}$; $u_{4}=\left\{u_{41}, u_{42}, u_{43}\right\} ; u_{5}=\left\{u_{51}, u_{52}\right\}$. The evaluation level $\mathrm{V}=\left\{v_{1}, v_{2}, v_{3}, v_{4}, v_{5}\right\},(90,80,70,60,50)$ used as the conversion score corresponding to the final score according to the degree of satisfaction.

\subsubsection{Determination of Fuzzy Evaluation Index Weight}

The higher the evaluation indicator score, the more critical this indicator is. Therefore, this paper uses the Analytic Hierarchy Process (AHP) method because it can make the value of weights more authentic through quantitative analysis.

1) Build fuzzy judgment coefficient matrix

Using the questionnaire survey data to obtain the judgment coefficient of the five evaluation words, the fuzzy judgment coefficient matrix of the five indicators is $u_{1}, u_{2}, u_{3}, u_{4}, u_{5}$. The judgment coefficients of all the first-level signs form the fuzzy judgment matrix.

$$
\begin{gathered}
u_{1}=\left(\begin{array}{lll}
0.222 & 0.244 & 0.089 \\
0.370 & 0.444 & 0.267 \\
0.370 & 0.274 & 0.548 \\
0.030 & 0.022 & 0.074 \\
0.007 & 0.015 & 0.022
\end{array}\right) u_{2}=\left(\begin{array}{ccc}
0.111 & 0.133 & 0.222 \\
0.200 & 0.444 & 0.370 \\
0.496 & 0.400 & 0.370 \\
0.178 & 0.022 & 0.022 \\
0.015 & 0 & 0.015
\end{array}\right) u_{3}=\left(\begin{array}{ccc}
0.178 & 0.044 & 0.089 \\
0.333 & 0.489 & 0.133 \\
0.400 & 0.407 & 0.444 \\
0.089 & 0.044 & 0.311 \\
0 & 0.015 & 0.022
\end{array}\right) \\
u_{4}=\left(\begin{array}{lll}
0.111 & 0.089 & 0.067 \\
0.200 & 0.200 & 0.148 \\
0.607 & 0.444 & 0.689 \\
0.067 & 0.222 & 0.096 \\
0.015 & 0.044 & 0
\end{array}\right) u_{5}=\left(\begin{array}{lll}
0.133 & 0.133 \\
0.370 & 0.252 \\
0.444 & 0.519 \\
0.040 & 0.081 \\
0.007 & 0.015
\end{array}\right)
\end{gathered}
$$

2) Determine the weight of each indicator

Using The Expert Rating Method and Delphi Method to assess the relative importance of the indicators, It uses the 1-9 scale method of the analytic hierarchy process (as shown in Table 2), forming the first-level index judgment matrix $\mathrm{C}$ and the second-level index judgment matrix $c, c_{1}, c_{2}, c_{3}, c_{4}, c_{5}$.

$$
\begin{gathered}
c=\left(\begin{array}{ccccc}
1 & 3 & 5 & 3 & 5 \\
1 / 3 & 1 & 3 & 4 & 4 \\
1 / 5 & 1 / 3 & 1 & 2 & 2 \\
1 / 3 & 1 / 4 & 1 / 2 & 1 & 3 \\
1 / 5 & 1 / 4 & 1 / 2 & 1 / 3 & 1
\end{array}\right) c_{1}=\left(\begin{array}{ccc}
1 & 1 / 3 & 3 \\
3 & 1 & 5 \\
1 / 3 & 1 / 5 & 1
\end{array}\right) c_{2}=\left(\begin{array}{ccc}
1 & 1 / 5 & 1 / 6 \\
5 & 1 & 1 / 2 \\
6 & 2 & 1
\end{array}\right) \\
c_{3}=\left(\begin{array}{ccc}
1 & \frac{1}{2} & \frac{1}{5} \\
2 & 1 & \frac{1}{7} \\
5 & 7 & 1
\end{array}\right) c_{4}=\left(\begin{array}{ccc}
1 & 3 & 3 \\
\frac{1}{3} & 1 & \frac{1}{2} \\
\frac{1}{3} & 2 & 1
\end{array}\right) c_{5}=\left(\begin{array}{cc}
\frac{1}{1} & 5 \\
\frac{1}{5} & 1
\end{array}\right)
\end{gathered}
$$

Table 2. Judgment matrix scale and its meaning.

\begin{tabular}{ll}
\hline Scaling & Definition and description \\
\hline 1 & This element is as important as another element \\
3 & This element is slightly more important than another \\
5 & This element is more important than another element \\
7 & This element is more important than another element \\
9 & This element is more important than another \\
$2,4,6,8$ & Denotes the need for a compromise between the above two \\
$1 / \mathrm{a}_{i j}$ & standards \\
\hline
\end{tabular}

In order to calculate the relative importance of the indicators, it is necessary to analyze vector variables, Based on research and experimentation, the "square root method" that applied to normalize the vectors is given by:

$$
\begin{gathered}
M_{1}=\sqrt[n]{\prod_{j=0}^{n} a_{i j}} i=1,2, \ldots, n \\
W_{i}=M_{i} / \sum_{j=0}^{n} M_{i}
\end{gathered}
$$

Where: $a_{i j}=$ Each element of the matrix;

$M_{1}=$ The product of the elements of the matrix;

$W_{i}=M_{i}$ is normalized;

To sum up, it finally obtain the feature vectors $\mathrm{A}$ and $W_{1}, W_{2}, W_{3}, W_{4}, W_{5}$ of the judgment matrix. 


$$
A=\left(\begin{array}{l}
0.454 \\
0.268 \\
0.118 \\
0.101 \\
0.059
\end{array}\right) W_{1}=\left(\begin{array}{l}
0.258 \\
0.637 \\
0.105
\end{array}\right) W_{2}=\left(\begin{array}{l}
0.081 \\
0.342 \\
0.577
\end{array}\right) W_{3}=\left(\begin{array}{l}
0.106 \\
0.150 \\
0.744
\end{array}\right) W_{4}=\left(\begin{array}{l}
0.593 \\
0.157 \\
0.249
\end{array}\right) W_{1}=\left(\begin{array}{l}
0.745 \\
0.255
\end{array}\right)
$$

\subsubsection{Evaluation Result}

Weighting the fuzzy evaluation matrix to obtain the first-level index fuzzy comprehensive evaluation decision set $B_{i}=u_{i} \cdot w_{i}$

$$
B_{1}=\left(\begin{array}{l}
0.222 \\
0.406 \\
0.328 \\
0.030 \\
0.014
\end{array}\right) \quad B_{2}=\left(\begin{array}{l}
0.183 \\
0.382 \\
0.390 \\
0.035 \\
0.010
\end{array}\right) \quad B_{3}=\left(\begin{array}{l}
0.092 \\
0.208 \\
0.434 \\
0.247 \\
0.019
\end{array}\right) B_{4}=\left(\begin{array}{l}
0.096 \\
0.187 \\
0.601 \\
0.098 \\
0.016
\end{array}\right) \quad B_{5}=\left(\begin{array}{l}
0.133 \\
0.340 \\
0.463 \\
0.050 \\
0.009
\end{array}\right)
$$

Determine the fuzzy evaluation matrix $\mathrm{U}=\mathrm{B}$. A

$$
\begin{array}{llllll}
\text { So } & \left(\mathrm{U}=B_{1}\right. & B_{2} & B_{3} & B_{4} & \left.B_{5}\right) \cdot A=
\end{array}
$$
$\left(\begin{array}{lllll}0.178 & 0.35 & 0.393 & 0.065 & 0.013\end{array}\right)^{\mathrm{T}}$, It can be seen that $17.8 \%$ of customers are very satisfied with the quality of express delivery services; $35 \%$ of customers are delighted; $39.3 \%$ of customers believe that the quality of express delivery services is ordinary; $6.5 \%$ of customers are not happy; $1.3 \%$ of customers are not very delighted with the quality of express delivery services. According to the corresponding discounted score (90, $80,70,60,50)$, the final score of the current express service quality is 76.08 . It shows that the courier service cannot efficiently meet the actual needs of customers, there is still room for improvement in the quality of courier services.

\section{Conclusion}

For this purpose, Improvements can be made from the SERVQUAL model-Tangible, Reliability, Responsiveness, Assurance and Empathy. In order to perfect Responsiveness, it can enhance training and establish a customer service concept, which can improve the ability of work. Finally, Improving timeliness and responsiveness of express service; In terms of reliability, we can use high technology to protect customer's personal information, while passer should pay attention to personal image, Because it can help the overall image of the service upgrade; For Empathy, By enhancing communication with customers, it can be provide them with personalized and high-quality services; For Security, Advancing facilities and equipment can be used to improve service quality. For Tangibility, we can though enhancing information feedback capabilities to sure the entire business process.

In the conclusion, FAHP is adopted to evaluate the construction of express service quality model. From the analysis, there is still room for improvement. The improvement of express service quality depends on the deep cooperation among express delivery companies, relevant government departments, consumers should adopt scientific management methods to improve the efficiency of service. However, restrictions on the number of questionnaires and evaluation indicators may affect the evaluation results. Can increase the sample size of the questionnaire and adjust the indicators to make the empirical results more scientific and authentic.

\section{Acknowledgements}

This study was supported by The National Key Research and Development Plan "Research and Application of Logistics Service Certification Scheme" (2016YFFo204105-1).

\section{References}

[1] Syed Abdul Rehman Khan, Dong Qianli, Yu Zhang. A Survey Study: Important Factors in Just-in-tie Implementation [J]. American journal of traffic and transportation engineering, 2017, 2 (5):74-80.

[2] Liu Longqing, Zhang Guoqing. A analysis of Status and Prospects of Reverse logistics Channel Management [J]. Commercial Times, 2014, (30):22-24.

[3] ChenPing, Yang Jinwei. Study on Quality Evaluation and Improvement Countermeasures of On-campus Express Delivery Services [J]. Logistics Technology, 2014, 33 (15):192-195

[4] WuJing, Zheng Xiaohong, Chen Xinguo. A analysis of Quality Factors in Return Logistics Service [J]. Journal of Commercial Economics, 2016, (17):101-103.

[5] Jie Fang. Empirical Research on the Relations between Online Shopping Customer Perceived Service Quality and Customer Repurchase Intention $[\mathrm{J}]$. The Theory and Practice of Finance and Economics, 2016, 37 (03):123-127.

[6] Zheng Jianing. "Who Moved My Information?"-Ownership and Protection of Express Service Information [J]. Lanzhou Academic Journal, 2016, (08):150-156.

[7] Fan Lixian, Ye Yuanhui. The Influence of Express Service Quality on Express Brand Satisfaction: Moderating Effect of Customer Experience on E-commerce Environment [J]. Foreign Economics \& Management, 2017, 39 (12):140-151.

[8] Cao Xia, Li Ling. Study on Evaluation System of Express Service Quality of Online Shopping based on SERVQUAL Model [J]. Railway Transport and Economy, 2015, 37 (08):93-98.

[9] Zheng Yuzhou, Zhang Huifeng, Wang Fan. Research on the Pricing Mechanism Reform of China's Express Service and Relevant Suggestion [J]. Prices Monthly, 2016, (04):12-17.

[10] Shi Li. Study on the construction of evaluation quality index system and influencing factors of express customer perception [J]. Theory \& Practice, 2017, (07):149-152. 